\title{
Efficacy and safety of metformin or oral contraceptives, or both in polycystic ovary syndrome
}

\author{
Young-Mo Yang \\ Eun Joo Choi \\ College of Pharmacy, Chosun \\ University, Gwangju, South Korea
}

\author{
This article was published in the following Dove Press journal: \\ Therapeutics and Clinical Risk Management \\ I September 2015 \\ Number of times this article has been viewed
}

Correspondence: Eun Joo Choi College of Pharmacy, Chosun University, 309 Pilmun-daero, Dong-gu, Gwangju 6I452, South Korea

Tel +82622306382

Fax +8262 222 54I4

Email ejchoi@chosun.ac.kr
Background: Polycystic ovary syndrome (PCOS) is an endocrinopathy that affects approximately $10 \%$ of reproductive-aged women throughout their lives. Women with PCOS present with heterogeneous symptoms including ovulatory dysfunction, hyperandrogenism, and polycystic ovaries. Therefore, lifelong individualized management should be considered. Pharmacological agents commonly used to manage the symptoms are metformin and oral contraceptive pills. Although these medications have been beneficial in treating PCOS symptoms, their efficacy and safety are still not entirely elucidated. This study aimed to report the efficacy and safety of metformin, oral contraceptives, or their combination in the treatment of PCOS and to define their specific individual roles.

Methods: A literature search of original studies published in PubMed and Scopus was conducted to identify studies comparing metformin with oral contraceptives or evaluating the combination of both in PCOS.

Results: Eight clinical trials involving 313 patients were examined in the review. The intervention dosage of metformin ranged from 1,000 to $2,000 \mathrm{mg} / \mathrm{d}$ and that of oral contraceptives was ethinylestradiol $35 \mu \mathrm{g}$ and cyproterone acetate $2 \mathrm{mg}$. Lower body mass index was observed with regimens including metformin, but increased body mass index was observed in monotherapy with oral contraceptives. Administration of metformin or oral contraceptives, especially as monotherapy, had a negative effect on lipid profiles. In addition, there are still uncertainties surrounding the effects of metformin or oral contraceptives in the management of insulin level, although they improved total testosterone and sex hormone-binding globulin levels. In the included studies, significant side effects due to metformin or oral contraceptives were not reported.

Conclusion: The clinical trials suggest that metformin or oral contraceptives are at least patient convenient, efficacious, and safe for the treatment of PCOS. However, well-designed, prospective, long-term, large-scale, randomized clinical trials are necessary to elucidate the efficacy and safety of metformin, oral contraceptives, or both in the treatment of PCOS, and to elucidate their individual roles in the treatment of this condition.

Keywords: polycystic ovary syndrome, metformin, oral contraceptive pill, ovulatory dysfunction, hyperandrogenism, efficacy, safety

\section{Introduction}

Polycystic ovary syndrome (PCOS) is a life-long endocrinopathy which affects approximately $10 \%$ of women in the reproductive age. ${ }^{1-3}$ Although its pathogenesis has not been clearly identified, genetics and lifestyle factors may cause the development of the major features of PCOS. ${ }^{4}$ Women with PCOS present with the following symptoms: ovulatory dysfunction, hyperandrogenism, and polycystic ovaries; however, 
Table I Diagnostic criteria for polycystic ovary syndrome

\begin{tabular}{|c|c|c|}
\hline NIH/NICHD, $1992^{5}$ & ESHRE/ASRM (Rotterdam criteria), $2004^{6}$ & Androgen excess society guideline, $2006^{7}$ \\
\hline $\begin{array}{l}\text { - Exclude other androgen excess } \\
\text { or related disorders } \\
\text { - Include the following (clinical or } \\
\text { biochemical hyperandrogenism or } \\
\text { both and menstrual dysfunction) }\end{array}$ & $\begin{array}{l}\text { - Exclude other androgen excess or related } \\
\text { disorders } \\
\text { - Include two of the following (clinical or } \\
\text { biochemical hyperandrogenism or both; } \\
\text { oligo- or anovulation; and polycystic ovaries) }\end{array}$ & $\begin{array}{l}\text { - Exclude other androgen excess or related } \\
\text { disorder } \\
\text { - Include the following (clinical or biochemical } \\
\text { hyperandrogenism or both and ovarian } \\
\text { dysfunction, polycystic ovaries, or both) }\end{array}$ \\
\hline
\end{tabular}

Abbreviations: NIH/NICHD, National Institutes of Health/National Institute of Child Health and Human Disease; ESHRE/ASRM, European Society for Human Reproduction and Embryology/American Society for Reproductive medicine.

variation in presentation exists between PCOS patients. ${ }^{1,3}$ Although obesity, insulin resistance, and hyperinsulinemia are not required for the diagnosis of PCOS (Table 1), they commonly occur in women with PCOS, increasing susceptibility to metabolic complications such as type 2 diabetes, hyperlipidemia, hypertension, fatty liver, and sleep apnea. ${ }^{3-8}$ Consequently, PCOS causes endocrine, metabolic, and cardiovascular symptoms in affected women.

Women with PCOS usually seek treatment to manage the androgen-related symptoms, menstrual-related disorders, and infertility. ${ }^{3,4,8}$ However, they also have various long-term complications which have been frequently underestimated. ${ }^{9}$ For instance, gestational diabetes and hypertensive disorders are more likely to occur in women with PCOS during pregnancy, and as they get older, metabolic diseases including glucose intolerance, type 2 diabetes, or hyperlipidemia are frequently observed. ${ }^{9}$ Therefore, lifelong follow-up and management for these patients at risk are needed to detect and prevent complications as early as possible.

The major treatment modalities in PCOS are designed to control hyperandrogenism and lower insulin levels with improved insulin sensitivity, but the long-term treatment for PCOS is currently controversial. ${ }^{10}$ The pharmacological agents commonly used in the treatment of PCOS include insulin sensitizers, oral contraceptive pills (OCPs), and antiandrogenic agents. ${ }^{1,11}$ The use of metformin, an insulin sensitizer, in women with PCOS resulted in the improvement of hyperinsulinemia, reduction of androgen levels, and improvement of menstrual irregularity. ${ }^{12}$ Metformin treatment also positively affected lipid profiles in PCOS women. ${ }^{13,14}$ However, metformin treatment is associated with lactic acidosis, even though its incidence is rare, and may cause gastrointestinal side effects (SEs) such as nausea, which often disappear with long-term use. , $^{10}$

OCPs may decrease androgen levels and increase sex hormone-binding globulins (SHBGs), which seems to impact positively the symptoms, such as hirsutism, acne, and alopecia, experienced by women with PCOS. ${ }^{15}$ It is also likely that OCPs have a positive effect on low-density lipoprotein cholesterol, high-density lipoprotein cholesterol, and total cholesterol, except for triglycerides. ${ }^{15}$ On the other hand, weight gain, cardiovascular, and thromboembolic events can occur with the use of OCPs. ${ }^{1,16-18}$ Therefore, it is important to consider the efficacy and safety of metformin and OPSs, to appropriately treat the symptoms that occur in women with PCOS.

The aims of this review were to report the efficacy and safety of metformin, OCPs, or the combination of both of these agents in the treatment of women with PCOS. In addition, we sought to define the roles of metformin and OCPs in the treatment of the symptoms that women with PCOS may experience.

\section{Methods}

A literature search was performed to identify clinical trials in women with PCOS, which evaluated the efficacy and safety of metformin, OCPs, or a combination of both agents. PubMed and Scopus were searched to find the clinical trials written only in English. The following search terms were used: metformin, contraceptives, and polycystic ovary syndrome. The reference lists of the selected articles and related reviews were used to identify additional articles. Two reviewers independently scanned the article titles and abstracts and identified relevant studies that may fulfill the following inclusion criteria: 1) only prospective studies were eligible, 2) reproductive-aged women with PCOS, 3) metformin or OCPs had to be used for the treatment of PCOS, and 4) end points must contain endocrine and metabolic parameters.

\section{Results}

On the basis of the literature search (Figure 1), eight eligible clinical trials were identified that met the inclusion criteria, and the relevant findings from the selected trials are presented in Tables 2-4. ${ }^{10,12,14,19-23}$ A total of 313 women with PCOS were enrolled in the trials. Approximately 81 women received metformin alone, 136 OCPs alone, and 96 the combination of metformin and OCP. The dose of metformin administered during the study periods ranged from 1,000 to $2,000 \mathrm{mg} / \mathrm{d}$. 


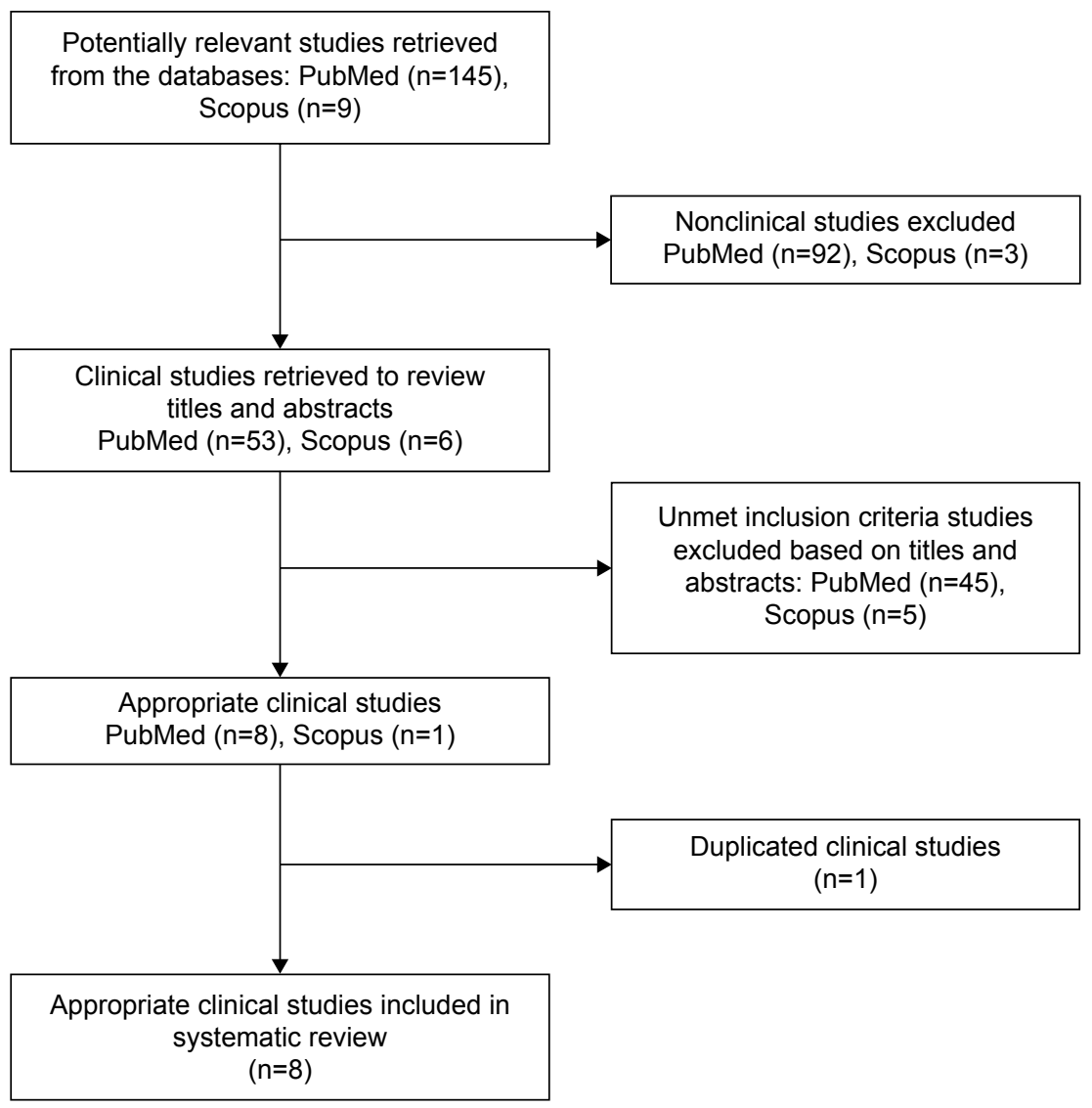

Figure I Flowchart of the study selection process.

The OCPs administered were mostly those containing ethinylestradiol $35 \mu \mathrm{g}$ and cyproterone acetate $2 \mathrm{mg}$.

A total of 90 women fulfilling the Rotterdam criteria for PCOS were enrolled in the randomized, controlled clinical trial conducted by Glintborg et $\mathrm{a}^{10}$ in Denmark. The patients received metformin $(2,000 \mathrm{mg} / \mathrm{d}), \mathrm{OCP}$ (desogestrel $150 \mathrm{mg}$ plus ethinylestradiol $30 \mu \mathrm{g}$ ), and metformin with the OCP for 12 months. The body mass index (BMI) decreased in the groups administered metformin, whereas it increased in the OCP monotherapy group. The insulin level was reduced only in the patients who received metformin with $\mathrm{OCP}$, and the total testosterone $(\mathrm{T})$ levels were decreased in all the three groups. Although the SHBG levels were increased in all three groups, the highest increase was observed in the OCP monotherapy group. A total of 25 patients were withdrawn from the trial, and adverse effects observed included depression and nausea.

Another randomized, double-blind, placebo-controlled trial in USA enrolled 23 overweight women with PCOS as defined by the modified Rotterdam criteria. ${ }^{19}$ The patients received either metformin $(1,500 \mathrm{mg} / \mathrm{d})$ with the OCP (ethinylestradiol $35 \mu \mathrm{g}$ plus norgestimate $0.18 / 0.215 / 0.25 \mathrm{mg}$ ) or the $\mathrm{OCP}$ with a placebo for 3 months. The BMI was decreased by $1.9 \%$ in the metformin plus OCP group $(P=0.006)$. The total cholesterol level was significantly increased in the OCP plus placebo group $(P=0.03)$. The total $\mathrm{T}$ levels were decreased in both groups, but the extent of these changes was higher in the OCP plus placebo group than it was in the metformin plus OCP group. The SHBG level showed more improvement in the OCP plus placebo group than it did in the metformin plus OCP group $(P=0.001)$. Four patients discontinued the trial, and one patient experienced heavy menstrual bleeding.

In the prospective randomized study conducted in Greece by Panidis et al, ${ }^{20} 45$ women with PCOS diagnosed in accordance with the NIH/National Institute of Child Health and Human Development criteria were divided into three groups: group A (ethinylestradiol $35 \mu \mathrm{g}$ plus cyproterone acetate $2 \mathrm{mg}$ ), group B (ethinylestradiol $30 \mu \mathrm{g}$ plus drospirenone $3 \mathrm{mg}$ ), and group C (metformin 1,700 mg/d). The treatments were continued for 6 months. The BMI was reduced by $5.6 \%$ in group $\mathrm{C}$, and their insulin level was decreased by 0.93 $\mu \mathrm{IU} / \mathrm{mL}$. The total $\mathrm{T}$ levels were significantly decreased in both groups A (31.01 ng/dL, $P=0.003)$ and B $(27.55 \mathrm{ng} / \mathrm{dL}$, 


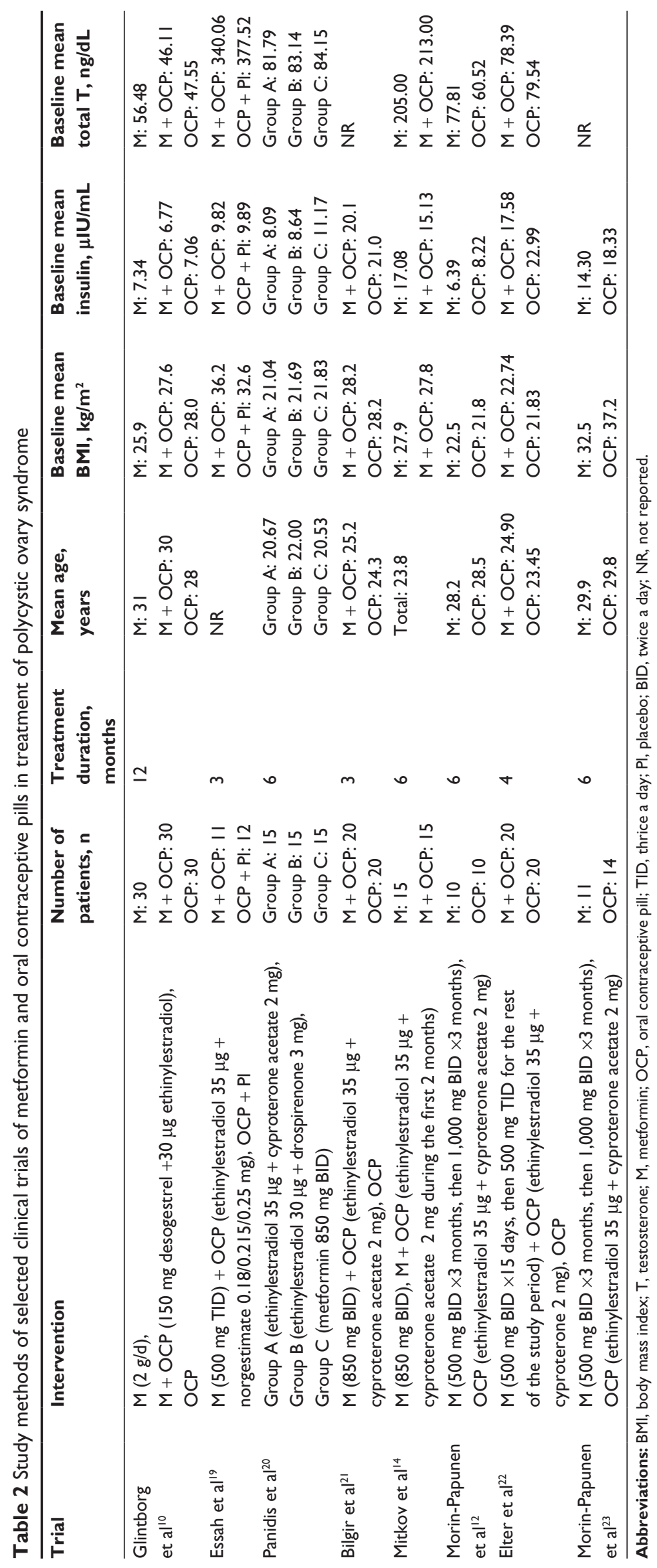




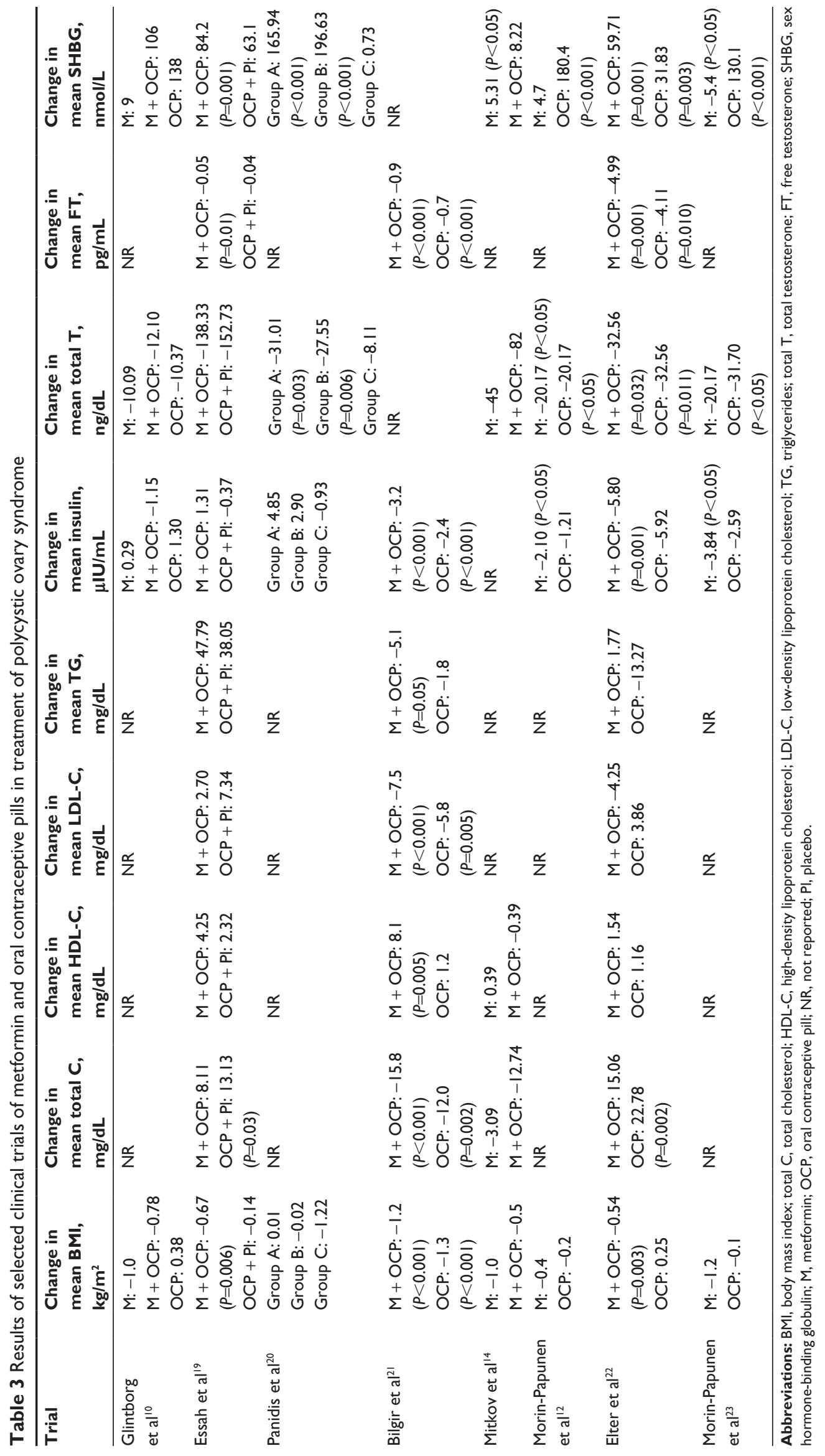


Table 4 Reasons for patient discontinuing selected clinical trials of metformin and oral contraceptive pills in treatment of polycystic ovary syndrome

\begin{tabular}{|c|c|c|}
\hline Trial & $\begin{array}{l}\text { Number of patient } \\
\text { withdrawals, } \mathbf{n}\end{array}$ & Reasons \\
\hline \multirow[t]{4}{*}{ Glintborg et al ${ }^{10}$} & M: II & M: pregnant $(n=I)$, wanted OCP $(n=2)$, depression $(n=I)$, \\
\hline & M+ OCP: 7 & nausea $(n=1)$, regrets $(n=4)$, lost to follow-up $(n=2)$ \\
\hline & OCP: 7 & $M+O C P$ : nausea $(n=3)$, regrets $(n=2)$, lost to follow-up $(n=2)$ \\
\hline & & OCP: wants pregnancy $(n=2)$, side effects $(n=3)$, lost to follow-up $(n=2)$ \\
\hline \multirow[t]{2}{*}{ Essah et $\mathrm{a}^{19}$} & $M+O C P: 2$ & $M+$ OCP: lost to follow-up $(n=I)$, moved away $(n=I)$ \\
\hline & $\mathrm{OCP}+\mathrm{PI}: 2$ & OCP + PI: lost to follow-up $(n=I)$, heavy menstrual bleeding $(n=I)$ \\
\hline \multirow[t]{3}{*}{ Panidis et $\mathrm{a}^{20}$} & Group A: 0 & - \\
\hline & Group B: 0 & \\
\hline & Group C: 0 & \\
\hline \multirow[t]{2}{*}{ Bilgir et a ${ }^{21}$} & $M+O C P: 0$ & - \\
\hline & OCP: 0 & \\
\hline \multirow[t]{2}{*}{ Mitkov et al ${ }^{14}$} & M: 0 & - \\
\hline & $M+O C P: 0$ & \\
\hline \multirow[t]{2}{*}{ Morin-Papunen et al ${ }^{12}$} & M: 2 & M: moved away $(n=l)$, personal reasons $(n=l)$ \\
\hline & OCP: I & OCP: headache and high blood pressure $(n=l)$ \\
\hline \multirow[t]{2}{*}{ Elter et $\mathrm{al}^{22}$} & $M+O C P: 0$ & - \\
\hline & OCP: 0 & \\
\hline \multirow[t]{4}{*}{ Morin-Papunen et $\mathrm{a}^{23}$} & M: 5 & M: moved away $(n=l)$, personal reasons $(n=l)$, manifest diabetes \\
\hline & OCP: 2 & mellitus $(n=2)$, continuous nausea and diarrhea $(n=l)$ \\
\hline & & OCP: manifested diabetes mellitus $(n=I)$, headache and \\
\hline & & high blood pressure $(n=1)$ \\
\hline
\end{tabular}

Abbreviations: $M$, metformin; OCP, oral contraceptive pill; PI, placebo.

$P=0.006$ ). Both groups A and B showed a significant increase in the SHBG levels $(165.94$ and $196.63 \mathrm{nmol} / \mathrm{L}$, respectively, $P<0.001$ ), while the SEs-related data were not reported.

A total of 40 women with PCOS, evaluated based on the Rotterdam criteria, were enrolled in the randomized clinical trial conducted by Bilgir et $\mathrm{al}^{21}$ in Turkey. The patients received either metformin $(1,700 \mathrm{mg} / \mathrm{d})$ with an OCP (ethinylestradiol $35 \mu \mathrm{g}$ plus cyproterone acetate $2 \mathrm{mg}$ ) or the OCP alone for 3 months. The BMI levels in the metformin plus OCP group and the OCP alone group were significantly decreased by $4.3 \%$ and $4.6 \%(P<0.001)$, respectively. The lipid profiles were improved in both groups. Significant reductions in the insulin level were observed in the metformin plus OCP and OCP alone groups (3.2 and $2.4 \mu \mathrm{IU} / \mathrm{mL}$, respectively, $P<0.001$ ), while the related SEs were not reported.

In the prospective, open clinical study conducted in Bulgaria by Mitkov et a ${ }^{14} 30$ women with PCOS diagnosed based on the Rotterdam criteria received either metformin $(1,700 \mathrm{mg} / \mathrm{d}$ ) alone or metformin plus OCP (ethinylestradiol $35 \mu \mathrm{g}$ plus cyproterone acetate $2 \mathrm{mg}$ for the first 2 months) for 6 months. The BMI levels improved in both groups, but this was not statistically significant. The high-density lipoprotein levels increased in the metformin alone group, but decreased in the metformin plus OCP group. Both groups showed an improvement in the SHBG levels, but only the metforminalone group showed a significant increase $(5.31 \mathrm{nmol} / \mathrm{L}$, $P<0.05)$. No patients discontinued the trial, and no serious SEs were reported.

Approximately 20 nonobese (BMI $<25 \mathrm{~kg} / \mathrm{m}^{2}$ ) women with PCOS as defined by Homburg ${ }^{24}$ were randomized to either a metformin group $(1,000 \mathrm{mg} / \mathrm{d}$ for 3 months, then $2,000 \mathrm{mg} / \mathrm{d}$ for 3 months) or OCP group (ethinylestradiol 35 $\mu \mathrm{g}$ plus cyproterone acetate $2 \mathrm{mg}$ for 6 months) in the clinical trial conducted by Morin-Papunen et $\mathrm{al}^{12}$ in Finland. The BMI levels improved in both groups, while a significant reduction $(2.10 \mu \mathrm{IU} / \mathrm{mL}, P<0.05)$ was observed in the insulin level of women in the metformin group. The total $\mathrm{T}$ levels were significantly decreased by $20.17 \mathrm{ng} / \mathrm{dL}(P<0.05)$ in both the metformin and OCP groups. The OCP group also showed a significant increase $(180.4 \mathrm{nmol} / \mathrm{L}, P<0.001)$ in the SHBG level. Three patients discontinued the trial, and one patient experienced headache and high blood pressure.

A prospective, randomized study was conducted in Turkey by Elter et al involving 40 women who were nonobese (BMI $<25 \mathrm{~kg} / \mathrm{m}^{2}$ ) with PCOS. ${ }^{22}$ They were administered either metformin $(1,000 \mathrm{mg} / \mathrm{d}$ for 15 days, and then $1,500 \mathrm{mg} / \mathrm{d}$ for the rest of study period) plus OCP (ethinylestradiol $35 \mu \mathrm{g}$ plus cyproterone $2 \mathrm{mg}$ ) or the OCP alone for 6 months. ${ }^{22}$ A significant reduction $\left(0.54 \mathrm{~kg} / \mathrm{m}^{2}\right.$, 
$P=0.003$ ) was observed in the BMI level of the metformin plus OCP group. The absolute reduction in the insulin level was higher in the OCP group than it was in the metformin plus OCP group; however, the reduction $(5.80 \mu \mathrm{IU} / \mathrm{mL}, P=0.001)$ was significant only in the metformin plus OCP group. A significant reduction was achieved in the total $\mathrm{T}$ levels of both the metformin plus OCP (32.56 ng/dL, $P=0.032)$ and OCP (32.56 ng/dL, $P=0.011$ ) groups. The SHBG levels were also significantly increased in both the metformin plus OCP (59.71 nmol/L, $P=0.001)$ and OCP $(31.83 \mathrm{nmol} / \mathrm{L}, P=0.003)$ groups. No patients were withdrawn from the trial, and only minor SEs were reported.

A total of 25 women who were obese and had PCOS as defined by Homburg ${ }^{24}$ were administered either metformin ( $1,000 \mathrm{mg} / \mathrm{d}$ for 3 months, then $2,000 \mathrm{mg} / \mathrm{d}$ for 3 months) or OCP (ethinylestradiol $35 \mu \mathrm{g}$ plus cyproterone acetate $2 \mathrm{mg}$ for 6 months) in the clinical trial conducted by Morin-Papunen et $\mathrm{al}^{23}$ in Finland. The BMI and insulin levels were improved in both groups, but the insulin level of the metformin group was significantly more decreased $(3.84 \mu \mathrm{IU} / \mathrm{mL}, P<0.05)$. A significant reduction $(31.70 \mathrm{ng} / \mathrm{dL}, P<0.05)$ was observed in the total T level of the OCP group. The SHBG level was significantly decreased in the metformin group $(5.4 \mathrm{nmol} / \mathrm{L}$, $P<0.05)$, but significantly increased in the OCP group (130.1 nmol/L, $P<0.001)$. Seven patients discontinued the trial during the study period, while two patients experienced nausea, diarrhea, headache, and high blood pressure.

\section{Discussion}

PCOS is a disease that occurs in approximately $10 \%$ of reproductive-aged women. ${ }^{1-3}$ Women with PCOS experience endocrine, metabolic, and cardiovascular symptoms, such as ovulatory dysfunction, hyperandrogenism, polycystic ovaries, obesity, insulin resistance, and hyperinsulinemia. ${ }^{1,3,4,8}$ Traditionally, metformin or OCPs have been used to ameliorate the symptoms experienced by women with PCOS. ${ }^{12-15}$ In this study, the efficacy and safety of metformin, OCPs, or a combination of both agents were determined using a literature search and analysis.

The clinical trials reviewed in this study demonstrated that metformin or OCPs have the potential to control the metabolic symptoms in women with PCOS. As shown in previous studies, the regimens that included metformin decreased the BMI levels. ${ }^{25-28}$ However, in cases where only the OCPs were administered, their effects on the BMI levels were not clear. In some studies included in this review, the BMI levels were increased in women treated with only the OCPs, but the changes were not high. ${ }^{10,20,22}$ Additionally, some studies reported changes in the lipid profiles; however, the effect of metformin or OCPs on the lipid profiles was not entirely clear. ${ }^{14,19,21,22}$ Metformin or OCPs, especially when only the OCPs were administered, did not consistently improve lipid profiles unlike the previous studies. ${ }^{13-15}$ Different doses of metformin and combination of metformin and OCPs probably led to this result that metformin did not show an apparent association with an improvement in lipid profiles. Taken together, the data from the clinical trials evaluated in this study suggest that the use of metformin may be beneficial in managing metabolic symptoms experienced by women with PCOS. In contrast, the effect of the OCPs on the metabolic symptoms was hardly conclusive based on the data reviewed in this study.

In this study, the effect of metformin or OCPs on endocrine symptoms was assessed. There are still uncertainties about the effects of metformin or OCPs in controlling insulin levels. Statistically significant reductions were usually observed when metformin was administered, regardless of the specific regimens administered to the patients. However, unfortunately, not all the women with PCOS responded to metformin with improved insulin levels. In particular, it was reported in some studies that metformin did not affect insulin sensitivity without weight loss in women with PCOS. ${ }^{29-31}$ Therefore, to optimize the beneficial effect of metformin on insulin levels, lifestyle modification interventions would also be necessary. ${ }^{32}$ In cases where the OCP was administered as monotherapy, the insulin levels were decreased compared with the baseline levels, although the OCP monotherapy was shown to affect negatively the insulin levels in some studies. ${ }^{10,20}$ Additionally, metformin and OCPs improved the total $\mathrm{T}$ and SHBG levels.

Metformin does not usually cause significant SEs, but its use may be associated with a rare, but serious SE called lactic acidosis. ${ }^{1,10,33-35}$ In the selected studies, gastrointestinal SEs such as nausea and diarrhea occurred in the patients administered metformin, which caused five patients to discontinue the trials. The use of OCPs can also cause SEs including weight gain as well as cardiovascular and thromboembolic events. ${ }^{1,16-18,36,37}$ Six patients who were administered OCPs discontinued the trials due to SEs such as headache, high blood pressure, and heavy menstrual bleeding. Although the total number of patients who discontinued the studies was small, the dropout rate of patients due to SEs could be relatively high when a small sample size is considered in each study. Long-term treatment of women with PCOS may be necessary because PCOS is a life-long endocrinopathy. ${ }^{1-3}$ Therefore, it is likely that the incidence rate of the metformin- or OCPs-related 
SEs may be higher than observed in the included studies. In addition, adverse cardiovascular and metabolic effects, such as venous and arterial thrombosis, associated with OCPs vary among different formulations, and it is not possible to implement large randomized controlled trials to be enough for the detection of differences between various OCPs with respect to rare SEs like venous and arterial thrombosis. ${ }^{38}$

This study had a few limitations which have to be mentioned. We searched two electronic databases (ie, PubMed and Scopus) to identify relevant studies, although there are numerous databases available. This limited search could have also limited our chances of finding additional relevant studies. The eight selected studies used different types of OCPs and various treatment durations ranging from 3 to 12 months, which may lead to inconclusive results regarding OCPs' efficacy. Most of the selected studies in women with PCOS also focused on evaluating the efficacy of metformin or OCPs for the treatment of PCOS and very few analyzed the metformin- or OCPs-related SEs. In addition, most of the included studies were conducted for durations of less than 1 year; therefore, they did not observe SEs associated with metformin or OCPs because longer treatment durations are more often associated with higher incidences of SEs. Therefore, future long-term studies are necessary to determine the safety of metformin or OCPs in the treatment of PCOS. Lastly, the same PCOS diagnostic criteria were not applied in the evaluation of all the women with PCOS included in the selected studies. The disparate diagnosis may also have led to some of the vague results observed in the included studies.

\section{Conclusion}

The clinical trials reviewed in this study suggest that metformin or OCPs can be at least efficacious and safe patientconvenient medications for the treatment of PCOS at this point. However, it is necessary to monitor PCOS women on these medications since rare SEs such as lactic acidosis or weight gain can occur by the long-term use of them. Further well-designed, prospective, long-term, large-scale, randomized clinical trials are also necessary to elucidate the efficacy and safety of metformin or OCPs in the treatment of women with PCOS and appropriately establish the role of these agents in the treatment of PCOS. In addition, studies regarding management strategies for PCOS patients in the prepubertal and postmenopausal periods are necessary in the near future.

\section{Acknowledgment}

This study was supported by a research fund from Chosun University, 2014.

\section{Disclosure}

The authors report no conflicts of interest in this work.

\section{References}

1. Domecg JP, Prutsky G, Mullan RJ, et al. Adverse effects of the common treatments for polycystic ovary syndrome: a systematic review and meta-analysis. J Clin Endocrinol Metab. 2013;98(12):4646-4654.

2. Johnson NP. Metformin use in women with polycystic ovary syndrome. Ann Transl Med. 2014;2(6):56. doi: 10.3978/j.issn.2305-5839. 2014.04.15.

3. Sirmans SM, Pate KA. Epidemiology, diagnosis, and management of polycystic ovary syndrome. Clin Epidemiol. 2013;6:1-13.

4. Setji TL, Brown AJ. Polycystic ovary syndrome: update on diagnosis and treatment. Am J Med. 2014;127(10):912-919.

5. Zawadski JK, Dunaif A. Diagnostic criteria for polycystic ovary syndrome. In: Givens JHF, Merriman G, editors. The Polycystic Ovary Syndrome. Cambridge, MA: Blackwell Scientific; 1992:377-384.

6. Rotterdam ESHRE/ASRM-Sponsored PCOS Consensus Workshop Group. Revised 2003 consensus on diagnostic criteria and long-term health risks related to polycystic ovary syndrome. Fertil Steril. 2004;81(1): $19-25$.

7. Azziz R, Carmina E, Dewailly D, et al. Positions statement: criteria for defining polycystic ovary syndrome as a predominantly hyperandrogenic syndrome: an androgen excess society guideline. J Clin Endocrinol Metab. 2006;91(11):4237-4245.

8. Saha L, Kaur S, Saha PK. Pharmacotherapy of polycystic ovary syndrome - an update. Fundam Clin Pharmacol. 2012;26(1):54-62.

9. Peigne M, Dewailly D. Long term complications of polycystic ovary syndrome (PCOS). Ann Endocrinol (Paris). 2014;75(4):194-199.

10. Glintborg D, Altinok ML, Mumm H, Hermann AP, Ravn P, Andersen M. Body composition is improved during 12 months' treatment with metformin alone or combined with oral contraceptives compared with treatment with oral contraceptives in polycystic ovary syndrome. J Clin Endocrinol Metab. 2014;99(7):2584-2591.

11. Conway G, Dewailly D, Diamanti-Kandarakis E, et al. The polycystic ovary syndrome: a position statement from the European society of endocrinology. Eur J Endocrinol. 2014;171(4):P1-P29.

12. Morin-Papunen L, Vauhkonen L, Koivunen R, Ruokonen A, MartikainenH, Tapanainen JS. Metformin versus ethinyl estradiol-cyproterone acetate in the treatment of nonobese women with polycystic ovary syndrome: a randomized study. J Clin Endocrinol Metab. 2003;88(1): $148-156$.

13. Rautio K, Tapanainen JS, Ruokonen A, Morin-Papunen LC. Effects of metformin and ethinyl estradiol-cyproterone acetate on lipid levels in obese and non-obese women with polycystic ovary syndrome. Eur J Endocrinol. 2005;152(2):269-275.

14. Mitkov M, Pehlivanov B, Terzieva D. Combined use of metformin and ethinyl estradiol-cyproterone acetate in polycystic ovary syndrome. Eur J Obstet Gynecol Reprod Biol. 2005;118(2):209-213.

15. Soares GM, Vieira CS, de Paula Martins W, Dos Reis RM, de Sa MF, Ferriani RA. Metabolic and cardiovascular impact of oral contraceptives in polycystic ovary syndrome. Int J Clin Pract. 2009;63(1):160-169.

16. Lopez LM, Edelman A, Chen M, Otterness C, Trussell J, Helmerhorst FM. Progestin-only contraceptives: effects on weight. Cochrane Database Syst Rev. 2013;7:CD008815. doi: 10.1002/14651858.CD008815. pub3.

17. Kaminski P, Szpotanska-Sikorska M, Wielgos M. Cardiovascular risk and the use of oral contraceptives. Neuro Endocrinol Lett. 2013;34(7): 587-589.

18. Kemmeren JM, Algra A, Grobbee DE. Third generation oral contraceptives and risk of venous thrombosis: meta-analysis. BMJ. 2001;323(7305): 131-134.

19. Essah PA, Arrowood JA, Cheang KI, Adawadkar SS, Stovall DW, Nestler JE. Effect of combined metformin and oral contraceptive therapy on metabolic factors and endothelial function in overweight and obese women with polycystic ovary syndrome. Fertil Steril. 2011;96(2): 501-504. 
20. Panidis D, Georgopoulos NA, Piouka A, et al. The impact of oral contraceptives and metformin on anti-Müllerian hormone serum levels in women with polycystic ovary syndrome and biochemical hyperandrogenemia. Gynecol Endocrinol. 2011;27(8):587-592.

21. Bilgir O, Kebapcilar L, Taner C, et al. The effect of ethinylestradiol (EE)/cyproterone acetate (CA) and EE/CA plus metformin treatment on adhesion molecules in cases with polycystic ovary syndrome (PCOS). Intern Med. 2009;48(14):1193-1199.

22. Elter K, Imir G, Durmusoglu F. Clinical, endocrine and metabolic effects of metformin added to ethinyl estradiol-cyproterone acetate in non-obese women with polycystic ovarian syndrome: a randomized controlled study. Hum Reprod. 2002;17(7):1729-1737.

23. Morin-Papunen LC, Vauhkonen I, Koivunen RM, Ruokonen A, Martikainen HK, Tapanainen JS. Endocrine and metabolic effects of metformin versus ethinyl estradiol-cyproterone acetate in obese women with polycystic ovary syndrome: a randomized study. J Clin Endocrinol Metab. 2000;85(9):3161-3168.

24. Homburg R. Polycystic ovary syndrome - from gynaecological curiosity to multisystem endocrinopathy. Hum Reprod. 1996;11(1):29-39.

25. Linneke JL, Jorgensen GK, Csillag C. Metformin for weight loss and control in patients with mood disorder. J Clin Psychiatry. 2014;75(10): e1140-e1141.

26. Bjorkhem-Bergman L, Asplund AB, Lindh JD. Metformin for weight reduction in non-diabetic patients on antipsychotic drugs: a systematic review and meta-analysis. J Psychopharmacol. 2011;25(3):299-305.

27. Jensterle Sever M, Kocjan T, Pfeifer M, Kravos NA, Janez A. Shortterm combined treatment with liraglutide and metformin leads to significant weight loss in obese women with polycystic ovary syndrome and previous poor response to metformin. Eur J Endocrinol. 2014; 170(3):451-459.

28. Nieuwenhuis-Ruifrok AE, Kuchenbecker WK, Hoek A, Middleton P, Norman RJ. Insulin sensitizing drugs for weight loss in women of reproductive age who are overweight or obese: systematic review and meta-analysis. Hum Reprod Update. 2009;15(1):57-68.
29. Pau CT, Keefe C, Duran J, Welt CK. Metformin improves glucose effectiveness, not insulin sensitivity: predicting treatment response in women with polycystic ovary syndrome in an open-label, interventional study. J Clin Endocrinol Metab. 2014;99(5):1870-1878.

30. Ehrmann DA, Cavaghan MK, Imperial J, Sturis J, Rosenfield RL, Polonsky KS. Effects of metformin on insulin secretion, insulin action, and ovarian steroidogenesis in women with polycystic ovary syndrome. J Clin Endocrinol Metab. 1997;82(2):524-530.

31. Diamanti-Kandarakis E, Kouli C, Tsianateli T, Bergiele A. Therapeutic effects of metformin on insulin resistant and hyperandrogenism in polycystic ovary syndrome. Eur J Endocrinol. 1998;138(3):269-274.

32. Domecg JP, Prutsky G, Mullan RJ, et al. Lifestyle modification programs in polycystic ovary syndrome: systemic review and metaanalysis. J Clin Endocrinol Metab. 2013;98(12):4655-4663.

33. Nasri H, Rafieian-Kopaei M. Metformin: current knowledge. J Res Med Sci. 2014;19(7):658-664.

34. Lalau JD. Lactic acidosis induced by metformin: incidence, management and prevention. Drug Saf. 2010;33(9):727-740.

35. Scheen AJ. Metformin and lactic acidosis. Acta Clin Belg. 2011;66(5): 329-331.

36. Brynhildsen J. Combined hormonal contraceptives: prescribing patterns, compliance, and benefits versus risks. Ther Adv Drug Saf. 2014;5(5): 201-213.

37. Dragoman MV. The combined oral contraceptive pill-recent developments, risk and benefits. Best Pract Res Clin Obstet Gynaecol. 2014;28(6): 825-834.

38. Yildiz BO. Approach to the patient: contraception in women with polycystic ovary syndrome. J Clin Endocrinol Metab. 2015;100(3):794-802.
Therapeutics and Clinical Risk Management

\section{Publish your work in this journal}

Therapeutics and Clinical Risk Management is an international, peerreviewed journal of clinical therapeutics and risk management, focusing on concise rapid reporting of clinical studies in all therapeutic areas, outcomes, safety, and programs for the effective, safe, and sustained use of medicines. This journal is indexed on PubMed Central, CAS,

\section{Dovepress}

EMBase, Scopus and the Elsevier Bibliographic databases. The manuscript management system is completely online and includes a very quick and fair peer-review system, which is all easy to use. Visit http://www.dovepress.com/testimonials.php to read real quotes from published authors. 